IZA DP No. 5649

Hidden Consequences of a First-Born Boy for Mothers

Andrea Ichino

Elly-Ann Lindström

Eliana Viviano

April 2011

Forschungsinstitut zur Zukunft der Arbeit Institute for the Study of Labor 


\title{
Hidden Consequences of a First-Born Boy for Mothers
}

\author{
Andrea Ichino \\ University of Bologna \\ and IZA
}

Elly-Ann Lindström

IFAU, Uppsala

Eliana Viviano

Bank of Italy
Discussion Paper No. 5649
April 2011

IZA
P.O. Box 7240
53072 Bonn
Germany

Phone: +49-228-3894-0

Fax: +49-228-3894-180

E-mail: iza@iza.org

\begin{abstract}
Any opinions expressed here are those of the author(s) and not those of IZA. Research published in this series may include views on policy, but the institute itself takes no institutional policy positions.

The Institute for the Study of Labor (IZA) in Bonn is a local and virtual international research center and a place of communication between science, politics and business. IZA is an independent nonprofit organization supported by Deutsche Post Foundation. The center is associated with the University of Bonn and offers a stimulating research environment through its international network, workshops and conferences, data service, project support, research visits and doctoral program. IZA engages in (i) original and internationally competitive research in all fields of labor economics, (ii) development of policy concepts, and (iii) dissemination of research results and concepts to the interested public.
\end{abstract}

IZA Discussion Papers often represent preliminary work and are circulated to encourage discussion. Citation of such a paper should account for its provisional character. A revised version may be available directly from the author. 


\section{ABSTRACT}

\section{Hidden Consequences of a First-Born Boy for Mothers}

We show that in the US, the UK, Italy and Sweden women whose first child is a boy are less likely to work in a typical week and work fewer hours than women with first-born girls. The puzzle is why women in these countries react in this way to the sex of their first child, which is chosen randomly by nature. We consider two explanations. As Dahl and Moretti (2008) we show that first-born boys positively affect the probability that a marriage survives, but differently from them and from the literature on developing countries, we show that after a first-born boy the probability that women have more children increases. In these advanced economies the negative impact on fertility deriving from the fact that fewer pregnancies are needed to get a boy is more than compensated by the positive effect on fertility deriving from the greater stability of marriages, which is neglected by studies that focus on married women only.

JEL Classification: E24, J13, J22, J23

Keywords: female labour supply, preference for sons, mothers' behaviour

Corresponding author:

Andrea Ichino

Dipartimento di Scienze Economiche

Università di Bologna

Piazza Scaravilli 2

40126 Bologna

Italy

E-mail: andrea.ichino@unibo.it

\footnotetext{
* The views expressed here are our own and do not necessarily reflect those of the Bank of Italy. We would like to thank Jerome Adda, Fabrizio Bernardi, Guy Michaels, Enrico Moretti and participants to various conferences and seminars for insightful comments. Ekim Cem Muyan provided outstanding assistantship in preparing the data. We are also grateful to the US Statistical Bureau of Census, to the UK Office for Censuses and Surveys, to the Bank of Italy and to Statistics Sweden that provided the data on which this research is based.
} 


\section{Introduction}

Women whose first child is a boy are less likely to work in a typical week and they do so for fewer hours than women with first-born girls. We observe this fact in the US, the UK, Italy and Sweden using representative samples of women aged between 18 and 55 who had their first child between 18 and 40. The estimates are statistically significant and translate into quantitatively relevant labor income losses over the lifetime. But the real puzzle is why women in these countries react in this way and by so much to the sex of their first child, which to a large extent is chosen randomly by nature. ${ }^{1}$

It is a puzzle because a large body of evidence for developing countries suggests that, if the first-born child is a girl, parents continue to procreate until a son arrives, while they tend to stop otherwise. For example, Jayachandra and Kuziemko (2009) show that the "desire for a son" of Indian parents induces them to wean their first-born girls faster, because breastfeeding suppresses post-natal fertility preventing the possibility to conceive again in order to have a boy. ${ }^{2}$ By contrast, having a first-born boy should give mothers more possibilities to work also because it reduces the number of pregnancies over the lifetime. This is indeed the finding of Chun and Oh (2002) for Korea who use the sex of the first child as an instrument for fertility in a labor supply equation for women, finding that mothers who have an additional child because their first-born child is a girl reduce the probability of labor force participation by $27.5 \%$.

We show that the puzzle is solved if we consider that in advanced economies the sex of the first child affects fertility in two opposite ways, of which only one is likely to be at work in less developed economies like the ones considered by the previously cited studies. As in these economies, also in advanced countries a first-born girl induces more fertility within married couples, because parents continue to procreate until they get a son (the "desire for a son" effect found e.g. by Dahl and Moretti, 2008). On the other hand, a first-born girl reduces substantially the stability of a marriage (the "divorce" effect). This second effect has been

\footnotetext{
${ }^{1}$ The gender of the first child is random at conception but not exactly random at birth because the success of pregnancies is slightly correlated with socio-economic characteristics of parents for biological and evolutionary reasons. For example, Catalano et al., (2005a,b) shows that the birth ratio increased after the September 11 attack or in times of high unemployment. Moreover, the sex of a born-alive child (also the first-born) is (weakly) correlated with socio-economic characteristics of the mother, making mothers in good condition more likely to have sons (Cox, 2007; Trivers and Willard, 1973). The definition of "good condition" may vary but for example Almond and Edlund (2007) find that better educated, married and younger women bear more sons. Oster (2005) describes the effect of hepatitis B as one of the causes of the birth sex ratio in favor of boys in many Asian countries, but her evidence, at least for China, has been widely criticized.

${ }^{2}$ The biological and behavioral literatures investigate the differences in breastfeeding duration by gender of the child. See, for example, Margulis, Altmann and Ober (1993).
} 
shown by Bedard and Dechéens (2004) without extending its implications to female labor supply. They find that the rate of marital dissolution is $4 \%$ higher for women whose firstborn child is a girl. ${ }^{3}$ We argue that since women in unstable marriages have fewer children over their lifetime, the sex of the first-born has ambiguous effects on fertility in countries where divorces are more likely and therefore the ambiguity extends to the effect on mothers' labor supply.

Interestingly, also Dahl and Moretti (2008), in their suggestive collage of evidence that American families prefer boys over girls, show both effects, i.e. that a first-born son increases the expected duration of marriages and reduces fertility in a sample of married couples. But they do not consider the full implications of their findings for the effect on fertility of a firstborn son on all women, independently of their marital status. We use their data and show that in the US, when all mothers are considered, a first-born son increases the number of children over the lifetime of a mother. And the same effect prevails in the UK, in Italy and in Sweden. In other words, the two effects of a first-born son act in opposite ways on fertility, but in advanced countries the "divorce" effect dominates the "desire for a son" effect, and, via the prevailing increase in fertility, a first-born boy reduces labour supply.

This result implies that the overall pattern of pregnancies, after the first one, may be affected by the sex of the first born. While the sex of the first child is randomly assigned, the sex and number of subsequent children is endogenous with respect to parental preferences and behaviour. For this reason Lundberg and Rose (2002), in their study of the relationship between labour supply and parenthood, fail to find evidence that the labour supply of women varies according to the sex of their full set of children. Although they focus correctly on all men and women, not just on married parents, they do not realize the endogeneity of the full parity. Only when the gender of the first born is considered without conditioning on marriage, the effect a child's sex on fertility and female labor supply emerges clearly, as shown in this paper.

\section{First child gender and mothers' labor supply.}

The facts that motivate this paper are described in Table 1. In the top panel we look at the mean weekly hours worked (except in Sweden where we observe only annual labor income).

\footnotetext{
${ }^{3}$ The "divorce" effect has been further studied also by Ananat and Michaels (2008) who use the sex of the first child as an instrumental variable to estimate, in quantile regressions, the causal effect of separations on women's income at different points of the income distribution.
} 
Non-employed people are included with zero hours to avoid possible bias determined by the fact that women self-select into employment. ${ }^{4}$ In the bottom panel we look at the probability that a woman is employed (the dependent variable is a dummy equal to one if the person declares to be employed). We focus on all women aged between 18 and 55 at the time of the interview, who had their first child between 18 and 40 years of age and whose first child is no more than 15 . We limit the sample at age 15 of the first-born child for two main reasons. First, children older than 15 may potentially enter the labour market and their decision may affect maternal labour supply, for instance because of income sharing within the household. Second, in the datasets we can identify only mothers with cohabiting children. Since in all the countries considered children tend to leave the household not before 18 and the time spacing between the first and the second child in our sample is around 3 years, the 15-year cut-off minimizes the possibility that we are measuring the sex of the second child instead of the first (just because the first has already left the household). Our estimates, in any case, are robust with respect to this cut-off. ${ }^{5}$

In the first column we use the 1980-2000 waves of the US Census. Consider first hours worked per week at the time of the interview as a measure of labour supply. The top panel of the first column shows that if the first-born child is a girl, mothers work on average 20.3 hours, but in the case of a boy the working time is reduced by $0.5 \%$. All these estimates are obtained controlling for a quadratic function of age and for interview year dummies. The bottom panel of the first column reports the probability of being employed, available for the Census waves from 1960 to 2000. On average, during the period, 53.6\% of the women whose first-born child is a girl are working. Since the sex of the first child is random, women whose first-born child is a boy are statistically identical to those who had a girl, but the probability to be employed of the former is $0.4 \%$ lower and the difference is statistically significant.

In column 2 and 3 of the same table we find that these results are confirmed using two other independent sources of data for the US: the Current Population Survey (CPS, for the years 1990-2008) and the National Health Interview Survey (NHIS, for the years 2005-2008). Actually, using these alternative data sources, with the same sample selection and the same regression specification, the estimated effects of a first-born boy are quantitatively larger and

\footnotetext{
${ }^{4}$ We have also carried out tobit estimates where the dependent variable is hours worked. They give even stronger results for all the countries.

${ }^{5}$ In particular, we have carried out estimates using a sample of mothers with children aged no more than 12 as in Dahl and Moretti (2008). This lower cut-off allows us to control for the fact that during the sixties in the US a non-negligible share of children used to leave the household around age 16. Our results are confirmed in this different sample and available upon request.
} 
at least equally significant despite the smaller sample sizes. Hours worked decrease by $-1.3 \%$ in the CPS and by $-2.7 \%$ in the NHIS, while the correspondent percent effects on the probability of working decreases by $0.5 \%$ in the CPS and by $1.3 \%$ in the NHIS.

Columns 4 and 5 of the table further show that these effects are observed not only in the US but also in the UK and in Italy, focusing on similarly defined samples of women and using the same regression specification. In the UK Census of 1991 (column 4) the hours worked per week in case of a girl are 12.4 and decrease by $1.9 \%$ in case of a boy. The probability of working in case of a first-born girl is $52.0 \%$ and decreases by $-1.4 \%$ in case of a boy. Similar results are reported in the fifth column for Italy. In this case the data come from the Labor Force Survey (LFS, for the years 2004-2008). As expected, Italy is the country where fewer women work ( $49 \%$ if the first-born child is a girl) and their employment rate is even lower, by $1.2 \%$, if the first-born child is a boy. In terms of hours worked per week the reduction due to a first-born boy is $1.3 \%$.

Finally, in Sweden the effect of a first-born boy on labour income used as a broader measure of labor supply, as for instance suggested by Gerber and Mitchell $(2009)^{6}$, is again negative and the size is comparable with what found for the other countries. The probability of working is still negatively affected by the sex of the first child even if the sign is not significant.

Therefore, in these countries and datasets mothers whose first-born child is a boy (because of a random choice of nature) work less than those who instead have a first-born girl. Over a lifetime these effects are quantitatively important and translate into large labor income losses. If we calculate this loss using the average hourly pay of a woman aged between 18 and 55 and we assume 35 years of lifetime work, these losses (using 2007 as the base year) amount to roughly 27,000 dollars in the US, to 16,000 euros for Italian women, 25,000 pounds for UK women and 35,000 krona in Sweden (slightly more than 5,000 US dollars). ${ }^{7}$

\footnotetext{
${ }^{6}$ Labour income incorporates increases of labor supply at both the extensive (hours) and the intensive (effort per hour) margins, inasmuch as effort per hour is reflected in the wage.

${ }^{7}$ These calculations are based on the data on earnings of women published by the US Census Bureau and the National Statistical Office, for US and UK respectively. Data for Italy are drawn from EU-SILC 2007, which report annual earnings, hours worked per week and months worked per year. Hourly wages are then estimated by assuming that on average women do not vary their working time during the year. All data refer to gross earnings. In order to calculate the lifetime value of the loss we have used a discount factor equal to $3 \%$. By the use of the MORG-CPS we have also carried out a regression where the dependent variable is labour income and the RHS variable is a dummy equal to 1 if the first child is a boy and 0 otherwise. As before these estimates are obtained using a sample of women who had their first-born child between age 18 and age 40 and whose child is not older than 15 in the reference period. According to these results, having a boy as first child costs 21 dollars per week more than having a girl, at least for the first 15 years of life of the first child. If we consider a worker with a stable employment working around 48 weeks per year, this loss is around 1,000 dollars per year.
} 
From a different perspective, our estimates also imply that in the US each year more than 50,000 women aged between 18 and 55 with at least 1 child do not work, simply because their first child is a boy. These figures are equal to 20,000 in Italy and 24,000 in the UK. ${ }^{8}$

This collage of evidence and its implications for lifetime earnings and employment rates are undoubtedly solid and cannot be disregarded. They are likely to depend directly and indirectly on a wide set of factors that will need to be explored. But what we find most interesting, and we study in this short note, is how they relate to the effects of a first-born child on fertility and marriage.

\section{The effects of a first-born son on fertility and marital stability}

A large body of evidence for developing countries ${ }^{9}$ suggests that if the first-born child is a girl, parents continue to procreate until a son arrives, while they tend to stop otherwise. A similar evidence is presented by Dahl and Moretti (2008) for the US. Because of this desire for a son effect, which implies more pregnancies in the case of a first-born girl, we should see less labor market participation among mothers of first-born girls. This effect should be greater in countries where economic, cultural and institutional factors do not allow pregnant women to do (some) work during pregnancy. But given the evidence described in the previous section, this cannot be the only effect at work in developed economies like the US, the UK, Sweden or Italy, where we see that it is a first-born son that reduces female labor supply.

Indeed in advanced economies the sex of the first child affects fertility in a second way that works in an opposite direction. As shown by Bedard and Dechénes (2004) the rate of marital dissolution is $4 \%$ higher for women whose first-born child is a girl. We refer to this second channel as to the divorce effect. Since women in unstable marriages have fewer children over their lifetime, the gender of the first-born child has ambiguous effects on fertility in countries where divorces are more likely. On the one hand, a first-born boy increases the probability of marital stability (the "divorce effect") and, as marital stability implies more births, it may also increase fertility. On the other hand, having a first-born boy reduces the need of other pregnancies (the desire for a son effect).

\footnotetext{
${ }^{8}$ We carried out a similar exercise on the American and Italian Time Use surveys. This additional evidence, not reported to save space but available upon request, confirms the results presented in this section. We find that women whose first child is a boy tend to spend more time at home with children, for care and surveillance and, consequently, to work less.

${ }^{9}$ See for example Jayachandra and Kuziemko (2009) and Chun and Oh (2002).
} 
We therefore argue that the effects of a first-born boy on fertility and marital stability should be estimated using the sample criteria and the specification of Table 1, which includes all women independently on their marital status. Our results are reported in Table 2. Here we consider all women aged between 18 and 55 who had their first child between 18 and 40 and whose first child is no more than 15 at the time of the interview. The dependent variable is equal to 1 if the woman has at least two children and zero otherwise. All specifications include a quadratic function of the age of the mother and year dummies.

For all countries and datasets the probability of having more than 1 child increases when the first-born child is a boy. All the estimates are statistically significant and the effect ranges between $0.5 \%$ and $2 \%$ in the US, $1.1 \%$ in the UK, $0.9 \%$ in Italy and $0.6 \%$ in Sweden. Thus, differently than in those developing countries for which some evidence exists, in the US, the UK, Italy and Sweden mothers whose first child is a boy have higher fertility and tend to work less.

Our claim is that this happens via the channel of greater marital stability induced by a first-born boy. This is a finding of Dahl and Moretti (2008) which we confirm in our datasets. The results are presented in Table 3 which reports regressions in which the dependent variable is equal to 1 if the women is married at the time of the interview, and 0 if never married, separated or divorced (widows are excluded). The sample selection is the same as in Table 1: women aged between 18 and 55 who had their first child between 18 and 40 and whose first child is aged no more than 15. Using the US Census, in column 1, the probability of marriage is $86.4 \%$ if the first-born child is a girl and increases by $0.05 \%$ in the case of a boy. The percent effects are considerably larger in the CPS $(0.2 \%)$. Again consistently with the findings of Table 1 and 2, the bigger effect is observed in the NHIS (0.7\%). In the UK, Italy and Sweden the results are in the same ball park of the US estimates. ${ }^{10}$

These results are therefore consistent with the hypothesis that in these advanced economies, which differ substantially from developing countries, mothers whose first child is a boy tend to work less because their marriage is more stable and its stability increases fertility.

\section{A missing result in the literature}

If both the "divorce" and the "preference for son" effects are at work in developed economies we should see different results depending on whether the analysis is restricted to women in

\footnotetext{
${ }^{10}$ We have carried out these estimates also for a sample of women aged at least 42 in order to control also for completed fertility and we obtained very similar results.
} 
married couples or is instead extended to all women independently of their marital status, and this explains why our results differ from Dahl and Moretti (2008). In Table 4 we compare the estimates of Dahl and Moretti (2008) for the US Census, which are based on a sample of only married women, with estimates obtained using all women in the same dataset. To replicate the sample selection of Dahl and Moretti (2008) we focus on women aged between 18 and 40, who must have had their first child in the same age range and whose first child must be not older than 12. Moreover, as in their specifications, all regressions include a quadratic function of age, educational attainment, race and year dummies. We cannot replicate exactly their estimates as we do not have access to the same US Census sub-samples they have (our data derives from a smaller share of the population), but our results closely resemble what they get.

Panel (a) reports estimates in which the dependent variable is the total number of children. If we consider only married women (column 1) a first-born boy reduces this measure of fertility but the estimated coefficient is statistically not significant, exactly as in Dahl and Moretti (2008). Columns 2, 3 and 4 are based instead on all women and the interesting finding is in the last column, which includes the gender of the first child, marital status and the interaction between these two variables. In this specification we see that in general a first-born boy has a small positive and significant effect on fertility, but if the woman is married the effect changes sign while remaining statistically significant. In other words, as in developing countries, a first-born boy reduces fertility among married couples but has the opposite effect on women in general.

The other panels of the table break the evidence by the number of children replicating the results obtained by Dahl and Moretti (2008). As in their paper, while the probability that a woman has at least two children after a first-born boy is positive (panel (b)), the probability of having three or more children or four or more children decrease significantly when the first child is male. Based on this evidence, Dahl and Moretti (2008) conclude that having a firstborn boy reduces fertility. We suggest the possibility that their result is affected by selection bias, because the probability that a woman has three or more children is strongly correlated with her marital status, as married women have on average more children than unmarried women. At the same time, the probability of being married is in turn influenced by the sex of the first-born child.

There are few other studies that focus explicitly on the relationship between the sex of children and parental labor market behavior. Most of them operate the same sample 
selection of Dahl and Moretti (2008), based on the parents being married, that we consider inappropriate for the question that this literature wants to address. For example, Wulff Pabilonia and Ward-Batt (2007) investigates the effect of the first child's gender on parental labor supply in the US. Their results are typically mixed and statistically insignificant, but they do find that Asian men work fewer hours compared to white men if they have a son. No effect is instead found for mothers of any race and ethnicity. Lundberg and Rose (2002), using PSID data, look at a sample of fathers and mothers and find some effect of the first child gender only on fathers. Differently than other studies they correctly base their estimates on all men independently of marital status. However, their estimates are affected by other sources of bias. First, their sample includes also men with no children and this heterogeneity is unlikely to be random. Second, they regress labour supply on the total number and sex composition of the boys and girls that men have, which, as we have argued above, is not randomly assigned.

\section{Conclusions}

We have shown that in the US, the UK, Italy and Sweden women whose first child is a boy are less likely to work in a typical week and they do so for fewer hours than women with firstborn girls. Our estimates are statistically significant and translate into quantitatively relevant labor income losses over the lifetime. The effect of the first child sex is the combined result of at least two important sets of channels. To begin with, a first-born son reduces fertility because fewer pregnancies are needed to have a son (the desire for a son effect). Because of lower fertility, mothers of first-born sons should work more, and this is typically the evidence found in developing countries. But the sex of the first child affects fertility also in an opposite way, by making the marriage more stable in case of a first-born boy (the divorce effect). We show that in advanced economies this effect dominates and fertility increases when the first child is a male. For this reason, in the countries that we consider, a first-born boy decreases maternal labor supply. These results highlight the importance of using data on all women not only on married women to study the effects of the first-child gender on mothers' labor market outcomes. 


\section{Data Appendix}

Census data for US refer to years 1960-2000 are collected within the IPUMS International project and are available at https://international.ipums.org/international/. They are roughly a $2 \%$ random sample of the US population in the Census years and contain both personal and household identifiers and socio-demographic characteristics. Not all information is available for all years.

Census data for UK refer to year 1991 and are collected within the IPUMS International project and are available at https://international.ipums.org/international/. They are roughly a $1 \%$ random sample of the UK population and contain both personal and household identifiers and socio-demographic characteristics.

Current Population Survey data are drawn from the NBER site http://www.nber.org/cps/. The universe is the civilian noninstitutional population of the United States living in housing units and members of the Armed Forces living in civilian housing units on a military base or in a household not on a military base. In this paper we use the March supplement, which includes detailed information not only on labor supply, but also on socio-demographic characteristics of individuals and households. About 57,000 households are currently interviewed, containing approximately 112,000 persons 15 years old and approximately 31,000 children 0-14 years old. We use data from 1990 to 2008.

National Health Interview Survey (NHIS) is conducted since 1957 and it is aimed at collecting information on a broad range of health topics. Data are collected yearly through cross-sectional household interview and are available for free at http://www.cdc.gov/nchs/about/major/nhis/. The sample over-weights both Black person and Hispanic persons and it covers roughly 35,000 households and 87,000 individuals. Basic demographic information is available for all household members.

The Italian labor Force Survey is conducted by the Italian Statical Office, Istat, and includes around 80,000 households and 200,000 individuals, which are interviewed in different weeks of the year. The sample units are "de facto" households, composed of people living together even if with no formal arrangement. Each year 4 releases are available, in January, April, July and October. Because of a break in the sample design and questionnaire in 2004, data comparability before 2004 is not ensured. The public-use files contain a household identifier 
and detailed socio-demographic characteristics also for individuals aged less than 16. Publicuse files are released by Istat, but they are not free of charge. As the CPS no retrospective information on fertility and marital status is included.

The Swedish data, provided by Statistics Sweden, is a population-wide panel data set (LISA) based on administrative records. Detailed socio-demographic variables are observed on a yearly basis for all individuals at least 16 years old. Moreover, households are identified and all children (regardless of age) are linked to their biological parents by the Multigenerational registry (Flergenerationsregistret). No information on hours worked is available. 


\section{References}

Almond, D. and L. Edlund (2007): Trivers-Willard at birth and one year: evidence from US natality data 1983-2001, Papers and proceedings of the Royal Society, 274: 2491-2496

Ananat E. O. and Michaels G. (2008), "The effect of marital breakup on the income distribution of women with children", The Journal of Human Resources, 43, 3, 611-629.

Bedard K. and O. Dechénes (2004), "Sex Preferences, Marital Dissolution, and the Economic Status of Women", The Journal of Human Resources, XL, 2, 411-434.

Catalano, R., T. Bruckner, J. Gould, B. Eskenazi and E. Anderson (2005a):, Sex ratios in California following the terrorist attacks of September 11, 2001, Human Reproduction, vol. 20 , no. 5

Catalano, R., T. Bruckner, E. Anderson and J. Gould (2005b): Fetal death sex ratios: a test of the economic stress hypothesis, International journal of Epidemiology, no. 34

Chun H. and Oh J. (2002), "An instrumental variable estimate of the effect of fertility on the labor force participation of married women", Applied Economics Letters, 9, 631-634.

Cox, Donald (2007): Biological basics and the economics of the family, Journal of Economic Perspectives, vol. 21, no. 2

Dahl G. B. and E. Moretti (2008), "The demand for sons", Review of Economic Studies, 75, $1085-1120$.

Gerber A. and J. W. Mitchell (2009), "Taxes and Time Allocation: Evidence from Single Women", NBER Working paper no. 15583.

Jayachandran S. and I. Kuziemko (2009), "Why do mothers breastfeed girls less than boys? Evidence and Implications for child health in India", NBER WP. no. 15041.

Lundberg, S. and E. Rose (2002), "The Effect of Sons and Daughters on Men's Labor Supply and Wages", Review of Economics and Statistics, 84 (2), 251-268

Margulis, S. W., Altmann J. and C Ober (1993), "Sex-biased lactational duration in a human population and its reproductive costs", Behavioral Ecology and Sociobiology, 32 , 41-45. 
Oster, E. (2005), Hepatitis B and the case of the missing women , Journal of Political Economy, 113 (6), 1163-1216.

Trivers, R. L. and D. E. Willard (1973): Natural selection of parental ability to vary the sex-ratio of offspring, Science, no. 179]

Wulff Pabilonia, S. and J. Ward-Batts (2007), “The Effect of Child Gender on Parents' Labor Supply: An Examination of Natives, Immigrants, and their Children", AEA papers and proceedings, $97(2)$, 402-406 
Table 1: First child gender and labor supply: US, UK, Italy and Sweden.

\begin{tabular}{cccccc}
\hline & US & & UK & Italy & Sweden \\
Census & CPS & NHIS & Census & LFS & LISA \\
$1960-2000$ & $1990-2008$ & $2005-2008$ & 1991 & $2004-2008$ & 2004 \\
\hline
\end{tabular}

The first child is a boy

St. err.

Baseline: The first child is a girl

St. err.

Percent effect $(\%)$

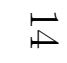

\section{(a) - Hours worked per week (Annual labour income in Sweden)}

$\begin{array}{cccccc}-0.092 & -0.200 & -0.464 & -0.232 & -0.195 & -5.790 \\ 0.021 & 0.071 & 0.087 & 0.139 & 0.078 & 2.864 \\ & & & & & \\ 20.294 & 15.491 & 17.460 & 12.358 & 15.272 & 1130.594 \\ 0.014 & 0.049 & 1.122 & 0.657 & 0.058 & 2.834 \\ -0.452 & -1.294 & -2.657 & -1.881 & -1.278 & -0.512\end{array}$

(b) - Probability of working

$\begin{array}{lcccccc}\text { The first child is a boy } & -0.002 & -0.003 & -0.008 & -0.007 & -0.006 & -0.001 \\ \begin{array}{l}\text { St. err. } \\ \text { Baseline: The first child is a girl }\end{array} & 0.000 & 0.002 & 0.006 & 0.005 & 0.002 & 0.001 \\ \text { St. err. } & 0.536 & 0.635 & 0.647 & 0.520 & 0.493 & 0.652 \\ \begin{array}{l}\text { Percent effect (\%) } \\ \text { Sample size }\end{array} & -0.000 & 0.001 & 0.003 & 0.021 & 0.002 & 0.001 \\ \text { S } & -0.502 & -1.269 & -1.406 & -1.160 & -0.153 \\ & & & & & \\ \end{array}$

Source and notes: Authors' calculations. Women aged between 18 and 55 who had their first child between 18 and 40 years and whose first child is aged no more than 15. In the top panel, for the US Census the dependent variable is equal to the number of hours worked per week in all jobs during the previous year. Data on hours worked are available only for the period 1980-2000. For the CPS, the NHIS and LFS, it is equal to the number of hours worked in the week preceding the interview. For the UK Census, it is equal to the usual working time in all jobs. For Sweden, it is equal to annual labor income (in hundreds SEK). In the bottom panel the dependent variable is a dummy equal to 1 if the person is employed and 0 otherwise, except for Sweden, in which case it is equal to 1 if the person has positive labour income, 0 otherwise. All models include a quadratic in age of the mother and year dummies. 
Table 2: First child gender and fertility in the US, the UK, Italy and Sweden.

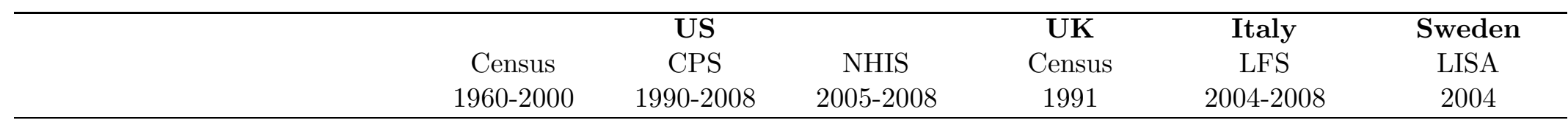

\section{Probability of having more than 1 child}

The first child is a boy

St. err.

Baseline: The first child is a girl

St. err.

Percent effect $(\%)$

Sample size

$\begin{array}{ll}0.003 & 0.005 \\ 0.000 & 0.002 \\ 0.641 & 0.625 \\ 0.000 & 0.001 \\ 0.489 & 0.845\end{array}$

\subsection{2}

0.005

0.614

0.041

1.993

$3,422,119$

25,339

0.007
0.004
0.656
0.020
1.127

0.005

$0.002 \quad 0.001$

$0.549 \quad 0.543$

$0.002 \quad 0.001$

$0.867 \quad 0.552$

Source and notes: Authors' calculations. Women who had their first child between 18 and 40 years and whose first child is aged no more than 15 . The dependent variables are dummies equal to 1 if the woman has at least 2 children and 0 otherwise. All models include a quadratic in age of the mother and year dummies. 
Table 3: First child gender and marital status of the mother in the US, the UK, Italy and Sweden.

\begin{tabular}{|c|c|c|c|c|c|c|}
\hline & $\begin{array}{c}\text { Census } \\
1960-2000\end{array}$ & $\begin{array}{c}\text { US } \\
\text { CPS } \\
1990-2008\end{array}$ & $\begin{array}{c}\text { NHIS } \\
2005-2008\end{array}$ & $\begin{array}{c}\text { UK } \\
\text { Census } \\
1991\end{array}$ & $\begin{array}{c}\text { Italy } \\
\text { LFS } \\
2004-2008\end{array}$ & $\begin{array}{c}\text { Sweden } \\
\text { LISA } \\
2004\end{array}$ \\
\hline & \multicolumn{6}{|c|}{ Probability of being married } \\
\hline The first child is a boy & 0.007 & 0.009 & 0.013 & 0.004 & 0.003 & 0.003 \\
\hline St. err. & 0.000 & 0.001 & 0.005 & 0.003 & 0.001 & 0.001 \\
\hline Baseline: The first child is a girl & 0.864 & 0.800 & 0.780 & 0.846 & 0.925 & 0.670 \\
\hline St. err. & 0.000 & 0.001 & 0.004 & 0.017 & 0.001 & 0.001 \\
\hline Percent effect $(\%)$ & 0.047 & 0.181 & 0.695 & 0.397 & 0.127 & 0.149 \\
\hline Sample size & $3,392,600$ & 300,535 & 23,121 & 44,813 & 196,445 & 699,873 \\
\hline
\end{tabular}

Source and notes: Authors' calculations. Women who had their first child between 18 and 40 years and whose first child is aged no more than 16 . The dependent variables are dummies equal to 1 if the woman is married and 0 otherwise. Widows are excluded. All models include a quadratic in age of the mother and year dummies. 
Table 4: Re-assessing the effect of first child gender on fertility in the US.

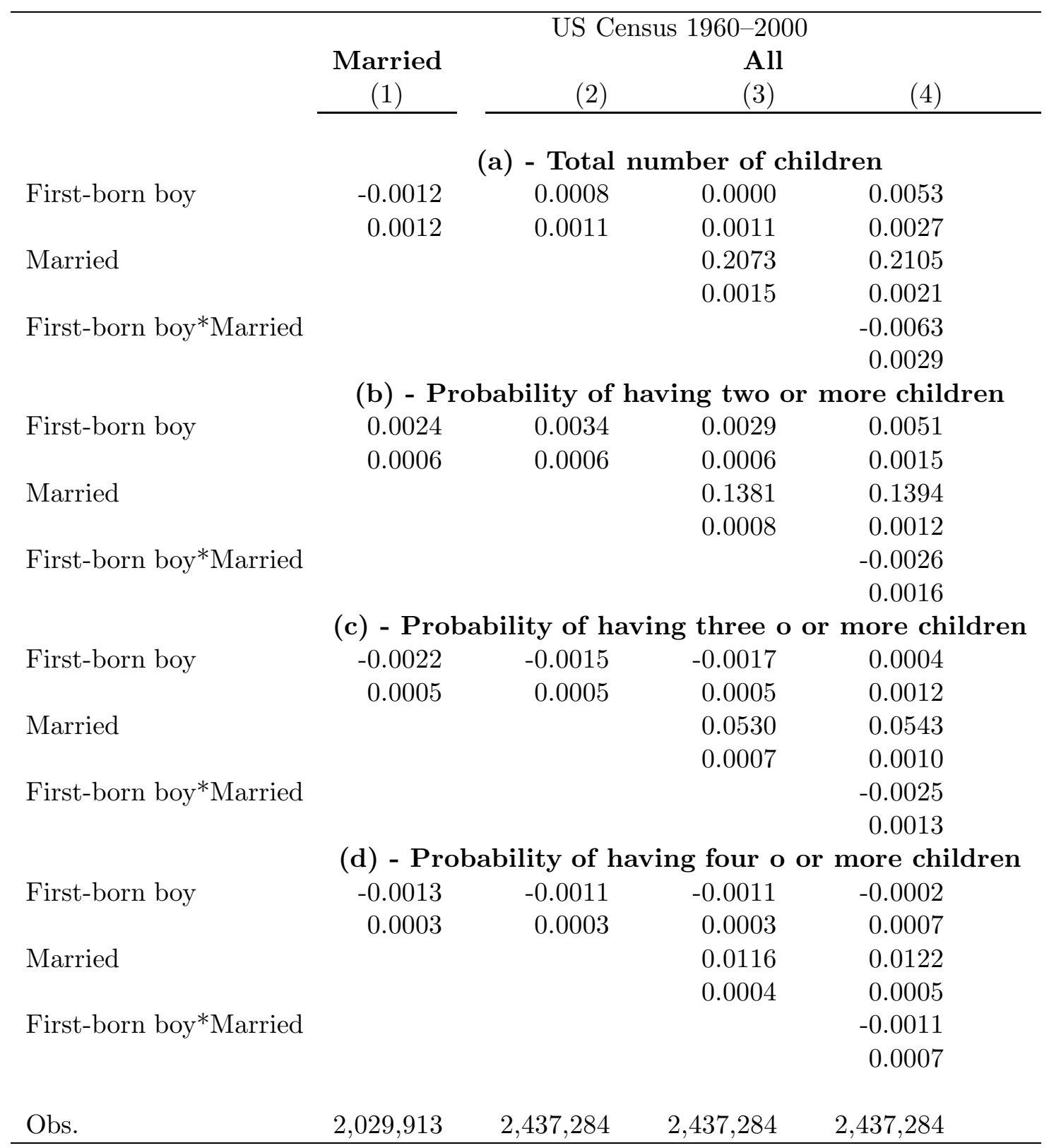

Source and notes: Authors' calculations. Women aged between 18 and 40 who had their first child between 18 and 40 years and whose first child is aged no more than 12, as in Dahl and Moretti (2008). To replicate Dahl and Moretti (2008) all models include a quadratic in age, educational attainment, race and year dummies. In panel (a) the dependent variable is the total number of children. In panels (b), (c) and (d) the dependent variables are dummies equal to 1 if the woman has two or more (three or more, four o more) children and 0 otherwise. 